\title{
The Effect of Different Levels of Coriander Oral Administration on Hepatocellular Carcinoma in Rats
}

\author{
Rasha H. Hasan ${ }^{1}$, Nehal M. Belal ${ }^{1,2, ~ *}$ \\ ${ }^{1}$ Home Economics Department, Basic Education Faculty, PAAET, Kuwait City, Kuwait \\ ${ }^{2}$ Nutrition and Food Science Dept. Faculty of Home Economics, Helwan University, Greater Cairo, Egypt \\ Email address: \\ drnohnoh@yahoo.com (N. M. Belal) \\ To cite this article: \\ Rasha H. Hasan, Nehal M. Belal. The Effect of Different Levels of Coriander Oral Administration on Hepatocellular Carcinoma in Rats. \\ Journal of Food and Nutrition Sciences. Vol. 3, No. 1, 2015, pp. 32-38. doi: 10.11648/j.jfns.20150301.15
}

\begin{abstract}
Background: Coriander (Coriandrum sativum L.) is grown as a spice crop all over the world. A few articles have linked the consumption of coriander to certain liver diseases but several articles have disputed these assertions and the consumption of coriander has been on the increase. Objective: This study aimed to determine the effects of oral administration of coriander on hepatocellular carcinoma in rats in order to compare biochemical findings with histological findings. Materials and Methods: Forty male and female albino rats were grouped into 5, consisting of 8 rats in each group. Group (1) was fed on the basal diet and tab water as a negative control group, while the other groups were fed on basal diet and injected with $\mathrm{C}$. Diethyl Nitrosamine (DEN) to induce hepatocellular carcinoma in rats. Group (2) was left as a positive control, while groups (3), (4), and (5) were fed on experimental diets and oral administration of $1 \mathrm{~g}, 3 \mathrm{~g}$, and $6 \mathrm{~g}$ of the Coriander, respectively, for 6 weeks.Their blood samples were analyzed for total and conjugated bilirubin, total protein, albumin, globulin, alanine aminotransferase, aspartate aminotransferase and alkaline phosphatase. The liver tissues were also processed for histological examination. Results: Examination of livers obtained from hepatocarcinogenesis rats in high concentration extract of coriander (6g) group revealed the best results compared with the other treatment groups in hepatic lobules. Conclusion:This study suggests that oral administration of coriander seed in high levels concentration extract for 6 weeks may be beneficial for patients suffering from hepatocarcinogenesis and liver disease as it improves liver function.
\end{abstract}

Keywords: Biochemical, Coriander, Hepatocarcinogenesis, Histology, Rats

\section{Introduction}

Coriander (Coriandrum sativum L.) is grown as a spice crop all over the world.Coriander is native to Southeastern Europe and grown extensively all over Europe, Middle East, China, India, and Turkey. ${ }^{[1]}$ It is recognized as cilantro in the west. This herbaceous plant grows up to 2 feet in height with branching stems, featuring deep green soft, hairless, bi or trilobed leaves. ${ }^{[2]}$ The mature plant bears small light pink color flowers that subsequently turn into globular or oval-shaped fruits (seeds). The seeds measure about 4-6 $\mathrm{mm}$ in diameter with central hollow cavity containing some important essential oils. ${ }^{[3]}$

The seeds are ready for harvest when the plants turn brown, leaves begin to dry and fall. Immature seeds are light green and taste bitter. To harvest, the crop is cut, tied in small bundles, and dried in the sunlight for several days. ${ }^{[4]}$ Traditionally, to separate the seeds, either the sheaves are beaten with stick or a lightweight roller used to wear off the pods. ${ }^{[5]}$

Spices and herbs are common dietary adjuncts that contribute to the flavor of foods. They are also known to exert beneficial physiological effects. ${ }^{[6]}$ Coriander (Coriandrum sativum ), commonly known as coriander or Chinese parsley, has been used as a foodstuff since at least the 10th century. ${ }^{[7]}$ Several physiological and medical benefits have been reported for the spice. In Iranian folk medicine, aqueous extract of Coriandrum sativum seed has been recommended for relief of anxiety and insomnia, and may have potential sedative, hypotensive, and muscle relaxant effects. ${ }^{[8],[9]}$

Coriandrum sativum seeds are also used to treat hyperglycemia and hyperlipidemia. Evidence for its efficacy against these conditions has been accumulated in animal models. [10] It has been reported to have several pharmacological effects such as antifertility, antihyperglycemic, antihyperlipidemic, antioxidant, antiprolife-rative and 
hypotensive activities. ${ }^{[11]}$ Chemical studies on $C$. sativum have shown the presence of constituents such as quercetin 3glucoronide linalool, camphor, geranyl acetate, geraniol and coumarins. ${ }^{[12],[13]}$

This plant is furthermore, believed to have carminative, diuretic and anticonvulsant effects. ${ }^{[13]}$ The aim of this study was to investigate the anticonvulsant effect of coriander seed extracts on the maximal electric seizures and pentylenetetrazole tests.

\section{Materials and Methods}

\subsection{Preparation of Plant Extracts}

The seeds of Coriandrum sativum were purchased from a local market, Cairo, Egypt. In Table 1 (Chemical composition of coriander nutrients).

Three preparations of $1 \mathrm{~g}, 3 \mathrm{~g}$, and $6 \mathrm{~g}$ of the coriander were put in $100 \mathrm{ml}$ tap water each and boiled for 5 minutes. The decoction was filtered with a No 1 Whatman filter paper and allowed to cool at room temperature. They were labeled $1 \mathrm{~g}, 3 \mathrm{~g}$, and $6 \mathrm{~g}$ respectively. ${ }^{[14]}$

Table 1. Depth analysis of nutrients: Coriander seeds (Coriander sativum) Nutritional value per 100 g. (Source: USDA National Nutrient data base).

\begin{tabular}{lll}
\hline Principle & Nutrient Value & Percentage of RDA \\
\hline Energy & $298 \mathrm{Kcal}$ & $15 \%$ \\
Carbohydrates & $54.99 \mathrm{~g}$ & $42 \%$ \\
Protein & $12.37 \mathrm{~g}$ & $22 \%$ \\
Total Fat & $17.77 \mathrm{~g}$ & $60 \%$ \\
Cholesterol & $0 \mathrm{mg}$ & $0 \%$ \\
Dietary Fiber & $41.9 \mathrm{~g}$ & $110 \%$ \\
Vitamins & & \\
Folates & $1 \mu \mathrm{g}$ & $<1 \%$ \\
Niacin & $2.130 \mathrm{mg}$ & $13 \%$ \\
Riboflavin & $0.290 \mathrm{mg}$ & $22 \%$ \\
Thiamin & $0.239 \mathrm{mg}$ & $20 \%$ \\
Vitamin A & $0 \mathrm{IU}$ & $0 \%$ \\
Vitamin C & $21 \mathrm{mg}$ & $35 \%$ \\
Electrolytes & & \\
Sodium & $35 \mathrm{mg}$ & $2 \%$ \\
Potassium & $1267 \mathrm{mg}$ & $27 \%$ \\
Minerals & & \\
Calcium & $709 \mathrm{mg}$ & $71 \%$ \\
Copper & $0.975 \mathrm{mg}$ & $108 \%$ \\
Iron & $16.32 \mathrm{mg}$ & $204 \%$ \\
Magnesium & $330 \mathrm{mg}$ & $83 \%$ \\
Manganese & $1.900 \mathrm{mg}$ & $82 \%$ \\
Phosphorus & $409 \mathrm{mg}$ & \\
Zinc & $4.70 \mathrm{mg}$ & \\
\hline
\end{tabular}

\subsection{Experimental Animals}

Forty albino rats were obtained from the National Research Center breeding farm, Cairo, Egypt, weighing $230 \pm 10 \mathrm{~g}$. They were housed in rat cages in a well ventilated house, temperature of $32 \pm 2^{\circ} \mathrm{C}$ during the day with $12 \mathrm{~h}$ natural light and $24 \pm 2^{\circ} \mathrm{C}$ in the night with $12 \mathrm{~h}$ darkness. The rats had free access to tap water and dry rat pellets. The rats were allowed to acclimatize for one week before the experiment.

\subsubsection{Preparation of Hepatocellular Carcinoma}

The chemical used in preparation of the carcinogen $\mathrm{C}$. Diethyl Nitrosamine (DEN) was of the purest grades Purchased from Sigma. A single dose of $150 \mathrm{mg}$ (DEN) $/ \mathrm{kg} /$ body weight of rats was injected intraperitoneally, where DEN was dissolved in a saline as the initiator and $1 \%$ ethanol given in drinking water after a week of injection. All the rats were placed under observation for 24 hours for possible deaths of the rats. ${ }^{[15]}$

\subsubsection{Experiments and Grouping of Rats}

Forty albino rats were used in this experiment in laboratory animals, depending on the animal ethical Committee. Rats were divided Into 5 equal groups of 8 rats each for 6 weeks as follows:

(1) Untreated control group(-); Animals was fed on a standard diet and given tap water.

(2) DEN group as control (+);Animals was injected with (DEN) $150 \mathrm{mg} / \mathrm{kg} /$ body wt , fed on a standard diet and given tap water.

(3) Coriander 1g group; Animals was injected with (DEN) $150 \mathrm{mg} / \mathrm{kg} /$ body wt, fed on a standard diet and were given oral administration of coriander $1 \mathrm{~g}$.

(4) Coriander 3g group; Animals was injected with(DEN) $150 \mathrm{mg} / \mathrm{kg} /$ body wt, fed on a standard diet and were given oral administration of coriander $3 \mathrm{~g}$.

(5) Coriander $6 \mathrm{~g}$ group; Animals was injected with(DEN) $150 \mathrm{mg} / \mathrm{kg} /$ body wt, fed on a standard diet and were given oral administration of coriander $6 \mathrm{~g}$.

During the feeding period, body weight gains (BWG\%) and food intake (FI) were calculated. ${ }^{[16]}$ At the end of experimental period, the rats were anesthetized by ether, and blood samples were collected. Blood samples were centrifuged for 20 minutes at $3000 \mathrm{rpm}$ to separate the serum which was kept at $-10^{\circ} \mathrm{C}$ till further biochemical analysis. Livers of the sacrificed rats were removed, liver weight and relative liver weight $(\%)$ were measured and preserved in $10 \%$ neutral formalin solution till further histopathological examination.

\subsection{Biochemical Analysis}

The blood samples were centrifuged; plasma aspirated and analyzed for bilirubin, total protein, albumin, globulin, alanine aminotransferase, aspartate aminotransferase and alkaline phosphatase according to standard biochemical methods.

\subsection{Bilirubin}

Plasma was added to a solution of sodium acetate and caffeine (sodium benzoate) which was then added to diazotized sulfanilic acid to form a purple azo bilirubin. The sodium acetate buffered the $\mathrm{pH}$ of the diazotized sulfanilic acid. The reaction was terminated by the addition of ascorbic acid which destroyed the excess diazo reagent A strongly alkaline tartrate solution was then added to convert the purple azobilirubin to blue azoblilrubin and the intensity of the color was measured at $600 \mathrm{~nm}$ with a spectrophotometer ${ }^{[17]}$ 


\subsection{Protein}

The peptide bonds of plasma protein in plasma reacted with biuret reagent which contained copper in alkaline solution to form a violet colored chelate which was measured with a spectrophotometer at $540 \mathrm{~nm} .{ }^{[18]}$

\subsection{Albumin}

Bromocresol green, a dye at an acid $\mathrm{pH}$ of 3.8 preferentially bound albumin to produce a shade of green color which was measured with a spectrophotometer at $630 \mathrm{~nm}$. ${ }^{[19]}$

\subsection{Alanine Aminotransferase}

Alanine aminotransferase catalysed the transfer of an amino group between the amino acids: L-alanine and Lglutamate. The ketoacids formed in this process were $\alpha$ ketoglutarate and pyruvate. The pyruvate formed reacted with dinitrophenylhydrazine to produce a corresponding dinitrophenylhydrazone, which was measured with the spectrophotometer at $505 \mathrm{~nm}$. ${ }^{[20]}$

\subsection{Aspartate Aminotransferase}

Aspartate aminotransferase catalysed the interco version of the amino acids: L-aspartate and L-glutamate to produce oxaloacetate and L-glutamate. The oxaloacetate then coupled with 2,4-dinitrophenylhydrazine to produce a brownish color hydrazone which was measured with the spectrophotometer at $505 \mathrm{~nm} .^{[21]}$

\subsection{Alkaline Phosphatase}

Alkaline phosphatase catalyzed the hydrolysis of 4nitrophenol phosphate forming phosphate and free 4nitrophenol, which in dilute acid solution was colourless. Under alkaline conditions 4-nitrophenol was converted to 4nitrophenoxide ion which had a very intense yellow color. The rate of formation of 4-nitrophenol by the addition of alkaline phosphatase on 4-nitrophenol at $37^{\circ} \mathrm{C}$ was then monitored at $405 \mathrm{~nm}$ with a recording spectrophotometer. ${ }^{[22]}$

\subsection{Histology}

Sections measuring approximately $0.2 \mathrm{~cm} \times 0.2 \mathrm{~cm}$ were taken from the liver of each rat. They were dehydrated through graded solutions of alcohol ending in two changes of absolute alcohol for 2 hours. They were cleared in 2 changes of xylene, infiltrated in 2 changes of paraffin wax for 2 hours each using the automatic tissue processor and embedded in molten paraffin wax. Sections were cut at $4 \mu$ with the rotary microtome and stained with haematoxylin and eosin . ${ }^{[23]}$

\subsection{Statistical Analysis}

Data were expressed as means \pm S.D. Statistical analysis was carried out using computerized SPSS program (version 8.0, Chicago, IL, USA) with student " $t$ " test for significance. [24]

\section{Result and Discussion}

Body weight and liver weight of rats animals of all groups were kept under close observation for intake of diet and fluid, rate of weight gain, and general health. There was no significant difference in final body weight, liver weight, or relative liver weight (percentage liver weight per body weight) among the groups (Table 2)

As shown in Table (2), feeding normal rats on basal diet for 6 weeks significantly increased body weight gain $(\mathrm{BWG} \%)$ and food intake $(\mathrm{FI})$, hepatocarcinogenesis rats on coriander oral administration significantly decreased BWG\% and FI in all groups especially in Control(+)(DEN)group , while hepatocarcinogenesis rats on coriander oral administration in high concentration $(6 \mathrm{~g})$ caused significant increases in $\mathrm{BWG} \%$ and FI compared with another oral administration levels of coriander. This finding was similar to that reported by ${ }^{[25]}$ who concluded that coriander extracted regulates appetite and has a promising effect on the body weight. ${ }^{[26]}$

In this study, various concentrations of coriander extract were utilized to investigate whether 1) coriander extract may play an important role in modulating redox status, and 2) the optimum intake of coriander may suppress hepatocarcinogenesis in carcinogen-treated rats. It was hypothesized that coriander extract may prevent hepatocarcinogenesis through modulation of the liver redox environment and oxidative stress, but that the chemopreventive effects may differ based on the concentration. ${ }^{[27]}$

It is clear from table 3 that all the biochemical markers investigated were little significantly decreased levels of the total protein and globulin, as compared to the control positive group. While, the levels of total bilirubin, conjugated bilirubin and albumin were little significantly increase in all treatment groups, as compared to the control positive group. Furthermore, the group of coriander $(6 \mathrm{~g})$ was the closest group in the results and parameters to the control group. This is in agreement with the results reported by Ilhan et al,2005. ${ }^{[28]}$

As demonstrated in table (4) that rat groups were treated with different levels of coriander oral administration treatment groups, for six weeks little significantly decreased the levels of AST, ALT and ALP enzymes in the serum, compared to the control positive group. The previous studies reported that different extracts of coriander effectively lower the elevated serum levels of AST, ALT and ALP enzymes. ${ }^{[29]}$

Coriander extract may play an important role in modulating redox status, and the optimum intake of coriander may suppress hepatocarcinogenesis in carcinogen-treated rats. It was hypothesized that coriander extract may prevent hepatocarcinogenesis through modulation of the liver redox environment and oxidative stress, but that the chemopreventive effects may differ based on the concentration. ${ }^{[30]}$

Coriander is a traditional medicine to treat a variety of disorders, including cancers. ${ }^{[31]}$ The DEN model for this study is a pre-clinical model of hepatocellular cancer that 
exhibits many phenotypic characteristics relevant to the liver cancer. It suggests that coriander has an antioxidant property, which may contribute to inhibition of lipid peroxidation, and suppress hepatocarcinogenesis. ${ }^{[32]}$

The biochemical observations reported in this study were supplemented by histopathological examination of liver sections of hepatocarcinogenesis rats. The obtained results showed that examination of livers of the normal (negative control ve) rats fed on the basal diet and water tab only had normal histological picture of hepatic lobule that consists of central vein surrounded by normal hepatocytes Fig. (1). Examination of liver of hepatocarcinogenesis rats showed severe fatty degeneration of the hepatocytes and infiltration of leucocytes in hepatic sinusoid (Fig. 2). Livers of hepatocarcinogenesis rats in coriander $(1 \mathrm{~g})$ group showed vacuolar degeneration of hepatocytes and fatty degeneration of hepatocytes as shown in Fig. (3). Examination of livers of hepatocarcinogenesis rats in coriander $(3 \mathrm{~g})$ group showed mild fatty degeneration of the hepatocytes as illustrated in (Fig.4). Hepatocarcinogenesis rats in coriander (6g) group showed little vacuolar degeneration of hepatocytes and decreasing leucocytic infiltration around central vein (Fig. 5). Examination of livers obtained from hepatocarcinogenesis rats in high concentration extract of coriander $(6 \mathrm{~g})$ group revealed almost normal hepatic lobules as illustrated in Fig.(5). Nearly similar histopathological findings were obtained by authors in $\mathrm{CCl} 4$ - hepatotoxic rats when given orally coriander extracts. ${ }^{[33],[34]}$

Table 2. Determination of final body weight, liver weight, or relative liver weight among the groups.

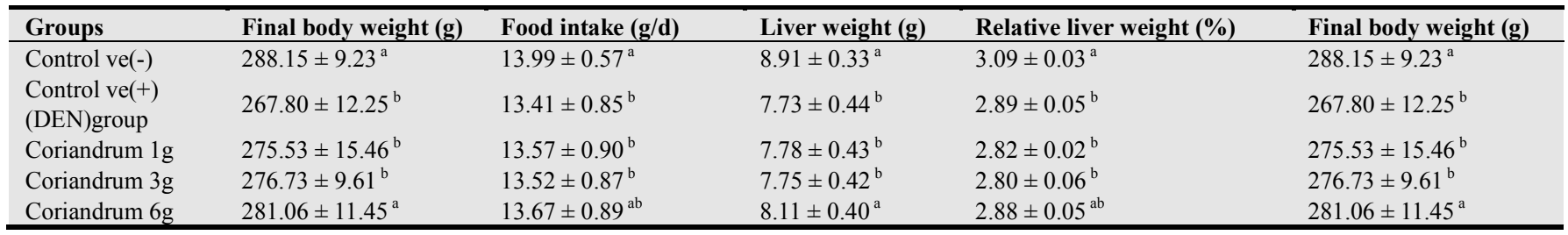

$\mathrm{a}, \mathrm{b}, \mathrm{c}, \mathrm{d}=$ means within the same classification followed by different letters significantly $(\mathrm{P}<0.05)$.

Relative liver weight $(\%)=[$ Liver weight $(\mathrm{g}) /$ Body weight $(\mathrm{g}) * 100]$.

All values are means \pm SE ( $=8$ per group), and "ns" means "not significantly different" among groups.

Table 3. Determination of the liver biochemical parameters.

\begin{tabular}{|c|c|c|c|c|c|}
\hline Groups & Total bilirubin $(\mu \mathrm{mol} / \mathrm{L})$ & Conjugated bilirubin $(\mu \mathrm{mol} / \mathrm{L})$ & Total protein $(\mathrm{g} / \mathrm{L})$ & Albumin (g/L) & Globulin (g/L) \\
\hline Control(-) & $12.10 \pm 2.14^{\mathrm{a}}$ & $5.32 \pm 1.12^{\mathrm{a}}$ & $66.05 \pm 2.53^{a}$ & $38.85 \pm 2.43^{a}$ & $27.15 \pm 3.24^{\mathrm{a}}$ \\
\hline $\begin{array}{l}\text { Control(+) } \\
\text { (DEN)group }\end{array}$ & $11.15 \pm 2.81^{\mathrm{c}}$ & $3.61 \pm 1.14^{\mathrm{c}}$ & $68.54 \pm 3.12^{c}$ & $36.17 \pm 3.07^{b}$ & $28.65 \pm 3.05^{\text {bc }}$ \\
\hline Coriandrum $1 \mathrm{~g}$ & $11.75 \pm 2.61^{b}$ & $3.62 \pm 1.24^{\mathrm{c}}$ & $68.15 \pm 0.68^{b c}$ & $36.56 \pm 2.43^{b}$ & $28.43 \pm 2.76^{b c}$ \\
\hline Coriandrum $3 \mathrm{~g}$ & $11.79 \pm 2.34^{\mathrm{bc}}$ & $3.75 \pm 1.22^{c}$ & $68.04 \pm 3.12^{b c}$ & $37.27 \pm 3.33^{b}$ & $28.00 \pm 2.03^{b}$ \\
\hline Coriandrum $6 \mathrm{~g}$ & $11.95 \pm 2.06^{\mathrm{bc}}$ & $4.11 \pm 1.69^{\mathrm{cd}}$ & $67.87 \pm 3.07^{b}$ & $37.88 \pm 1.337^{\mathrm{ab}}$ & $27.75 \pm 2.11^{\mathrm{ab}}$ \\
\hline
\end{tabular}

$\mathrm{a}, \mathrm{b}, \mathrm{c}, \mathrm{d}=$ means within the same classification followed by different letters significantly $(\mathrm{P}<0.05)$.

Table 4. Determination of the liver enzymes.

\begin{tabular}{|c|c|c|c|}
\hline $\begin{array}{ll}\text { Groups } & \text { Parameters } \\
\end{array}$ & $\operatorname{ALT}(\mathbf{I U} / \mathbf{L})$ & AST (IU/L) & ALP (IU/L) \\
\hline Control(-) & $25.85 \pm 1.73^{\mathrm{a}}$ & $20.84 \pm 1.44^{\mathrm{a}}$ & $75.35 \pm 2.51^{\mathrm{a}}$ \\
\hline $\begin{array}{l}\text { Control(+) } \\
(\mathrm{DEN}) \text { group }\end{array}$ & $28.63 \pm 1.34^{\mathrm{d}}$ & $22.84 \pm 2.13^{c}$ & $77.45 \pm 2.06^{\mathrm{c}}$ \\
\hline Coriandrum $1 \mathrm{~g}$ & $28.53 \pm 2.15^{d}$ & $22.75 \pm 2.06^{\mathrm{c}}$ & $76.93 \pm 3.71^{\mathrm{c}}$ \\
\hline Coriandrum $3 \mathrm{~g}$ & $28.16 \pm 1.04^{\mathrm{cd}}$ & $21.95 \pm 1.42^{b}$ & $76.83 \pm 3.29^{c}$ \\
\hline Coriandrum $6 \mathrm{~g}$ & $27.75 \pm 1.21^{\mathrm{bc}}$ & $21.13 \pm 2.66^{\mathrm{ab}}$ & $76.11 \pm 2.19^{b c}$ \\
\hline
\end{tabular}

$\mathrm{a}, \mathrm{b}, \mathrm{c}, \mathrm{d}=$ means within the same classification followed by different letters significantly $(\mathrm{P}<0.05)$.

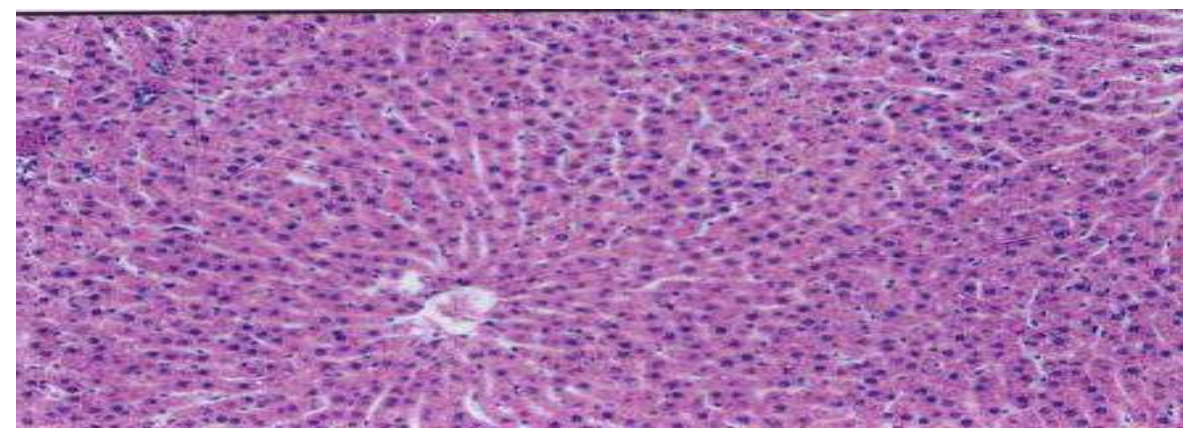

Figure 1. Liver of control C-ve (normal) rats showing normal histology of hepatic lobule. H\& E X 100). 


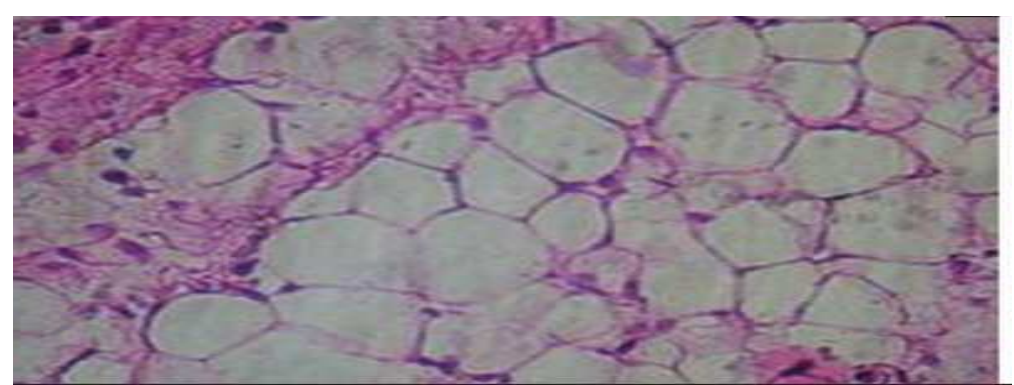

Figure 2. Liver of hepatocarcinogenesis (DEN control $C+v e$ ) rats showing severe fatty degeneration of hepatocytes and infiltration of leucocytes in hepatic sinusoid. (H\&EX 100).

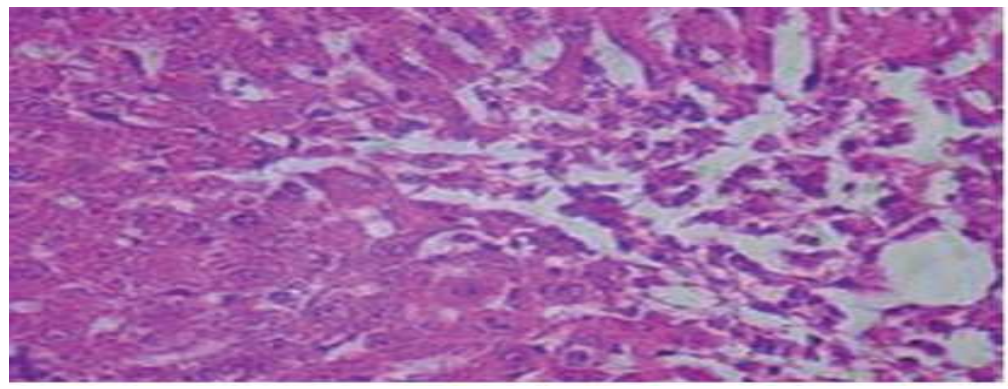

Figure 3. Liver of rats hepatocarcinogenesis rats in coraindrum (lg) group showing vacuolar degeneration of hepatocytes and fatty degeneration of hepatocytes. ( $H \& E X 100)$.

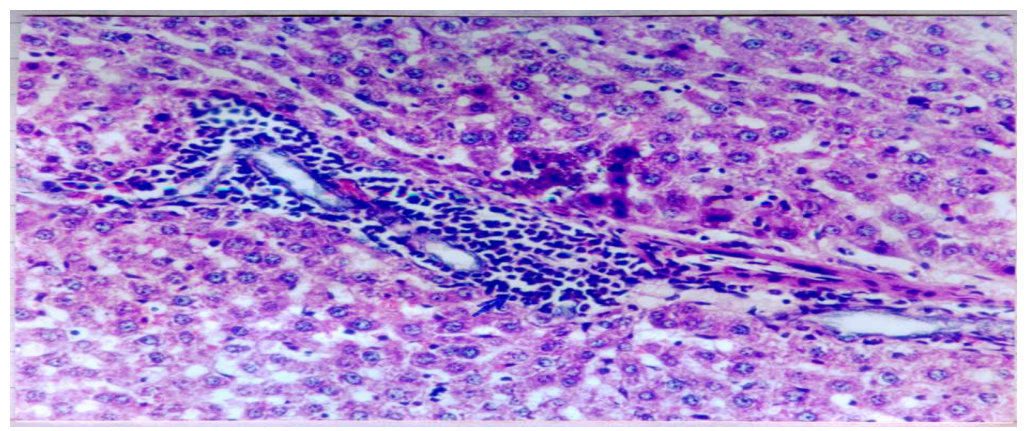

Figure 4. Liver of hepatocarcinogenesis rats in coraindrum (2g) group showing mild fatty degeneration of hepatocytes (H\& EX 100).

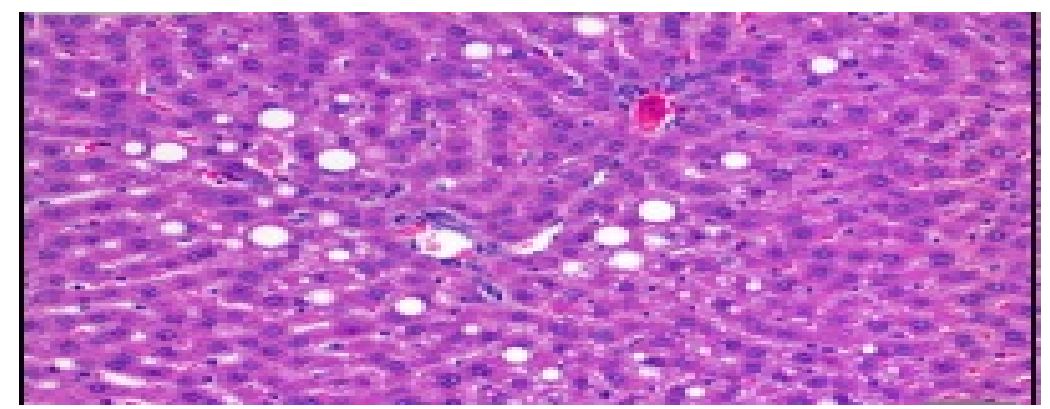

Figure 5. Liver of hepatocarcinogenesis rats in coraindrum (4g) group showing little vacuolar degeneration of hepatocytes and decreasing leucocytic infiltration around central vein. (H\& EX 100)

\section{Conclusion}

This study suggests that oral administration of coriander seed in high levels concentration extract for 6 weeks may be beneficial for patients suffering from hepatocarcinogenesis and liver disease as it improves liver function. Moreover, it produces an excellent effect on the histology of liver as it ameliorates the hepatic damage seen in the liver of hepatocarcinogenesis rats.

\section{References}

[1] Eidi M, Eidi A, Saeidi A, Molanaei S, Sadeghipour A, Bahar M, Bahar K.,2009. Effect of coriander seed (Coriandrum sativum L.) ethanol extract on insulin release from pancreatic beta cells in streptozotocin-induced diabetic rats. Phytother Res. 2009 Mar; 23(3):404-6. doi: 10.1002/ptr.2642. 
[2] Srinivasan K. Plant foods in the management of diabetes mellitus: spices as beneficial antidiabetic food adjuncts. Int J Food Sci Nutr. 2005;56(6):399-414

[3] Uchibayashi M. The coriander story. Yakushigaku Zasshi. 2001; 36(1):56-7.

[4] Medhin DG, Hadhazy, Bakos P, Verzar-Petri G. Hypotensive effects of Lupinus termis and Coriandrum sativum in Anaesthetized Rats. A preliminary study. Acta Pharm Hung. $1986 ; 56(2): 59-63$.

[5] Swanston-Flatt SK, Day C, Bailey CJ, Flatt PR. Traditional plant treatments for diabetes: studies in normal and streptozotocin diabetic mice. Diabetologia. 1990; 33: 462-4.

[6] Emamghoreishi M, Khasaki M and Aazam MF : Coriandrum sativum: evaluation of its anxiolytic effect in the elevated plus-maze. J Ethnopharmacol.2005, 15;96(3):365-70.

[7] Gray AM, Flatt PR. Insulin-releasing and insulin-like activity of the traditional anti-diebetic plant Coriandrum sativum (coriander). Br J Nutr. 1999; 81: 203-9.

[8] Chithra V, Leelamma S. Hypolipidemic effect of coriander seeds (Coriandrum sativum): mechanism of action. Plant Foods Hum Nutr. 1997; 51: 167-72.

[9] Chithra V, Leelamma S. Coriandrum sativum changes the levels of lipid peroxides and activity of antioxidant enzymes in experimental animals. Indian J Biochem Biophys. 1999; 36: 59-61.

[10] Weber N, Schöwiese S, Klein E, Mukherjee KD. Adipose tissue triacylglycerols of rats are modulated differently by dietary isomeric octadecenoic acids from coriander oil and high oleic sunflower oil. J Nutr. 1999; 129: 2206-11.

[11] Nakano Y, Matsunaga H, Saita T, Mori M, Katano M, Okabe H. Antiproliferative constituents in Umbelliferae plants II. Screening for polyacetylenes in some Umbelliferae plants, and isolation of panaxynol and falcarindiol from the root of Heracleum Moellendorffii. Biol Pharm Bull. 1998; 21: 257-61.

[12] Khrenova DK, Dargaeva TD, Nikolaev SM, Fedotovskikh NN, Brutko LI. Qualitative phytochemical analysis of antiulcerous drug prepared from plants. Farmatsiya Moscow. 1986; 35: 46-8.

[13] Zargari A. Medicinal Plants. Tehran: Tehran University 2002 Press; 1369: 580-90.

[14] Mabrouk GM, Moselhy SS, Zohny SF, Ali EM, Helal TE, Amin AA and Khalifa, AA (2002) Inhibition of methylnitrosourea (MNU) induced oxidative stress and carcinogenesis by orally administered bee honey and Nigella grains in Sprague Dawely rats. J Exp Clin Cancer Res 21: 341-346.

[15] Attalla F. El-kott, Ahmad A. Kandeel, Sayed F. Abed El-Aziz and Heba M. Ribea, 2013. The Histopathological, Immunohistochemical And Ultrastructural Alterations Following Administration Of Nigella Sativa In Rats Hepatocellular Carcinoma. Cancer Therapy Vol. 9, 30-39, 2013.

[16] Bhuiyan M. N. I., J. Begum, and M. Sultana, "Chemical composition of leaf and seed essential oil ofCoriandrumsativum L. from Bangladesh," Bangladesh Journal of Pharmacology, vol. 4, no. 2, pp. 150-153, 2009.

[17] Steven CK. Total bilirubin. Principle of analysis and current usage. In Liver function, In Clinical chemistry theory, analysis and correlation. James JT., Jenifer R. eds. M. Mosby, London 3rd ed. 1996; 504-527.

[18] Doumas BT, Bayse D, Borner K, Cart RJ, Peters T, Schaffer R. A candidate reference method for the determination of total protein in serum: Development and validation .Clin Chem 1981; 27: 1642-1650.

[19] Gustafsson JEC. Improved specificity of serum albumin determination and estimation of acute phase reactant" by the use of bromocresol green reaction. Clin Chem 1976; 22: 616622 .

[20] Bergmeyer, H.U.; Schreiber, P. and Wahlefeld, A.W. Optimization of methods for aspartate and alanine aminotransferases. Clin. Chem. 1978; 24: 58-61.

[21] Steven CK. Alanine and Aspartate aminotransferase, principle and usage. In Liver function, In Clinical chemistry theory, analysis and correlation. James JT., Jenifer R. eds. M. Mosby, London 3rd ed. 1996; 504-527.

[22] Juliet RH, John AL. Alkaline phosphatase, principle of analysis and current usage. In Liver function, In Clinical chemistry, theory, analysis and correlation. James JT., Jenifer R. eds. M. Mosby, London 3rd ed. 1996; 504-527

[23] Avwioro OG. Histochemistry and tissue pathology: Principles and techniques 1st ed, Claverianum press. Nigeria 2010.

[24] SPSS. (2007): Statistical Package for Social Science, SPSS Inc., Chicago, IL, USA Copyright $(\mathrm{C}$ for Windows, version 16.0 (2007).

[25] Hasan TN, Shafi G, Syed NA, Alfawaz MA, Alsaif MA, Munshi A, Lei KY, Alshatwi AA (2013) Methanolic extract of Nigella sativa seed inhibits $\mathrm{SiHa}$ human cervical cancer cell proliferation through apoptosis. Nat Prod Commun ;8(2):213-6.

[26] Jones AL. Anatomy of the normal liver. In: Zakin D, Boyer TD, Eds. Hepatology: a textbook of liver disease, 3rd ed. Philadelphia: WB Saunders, 1996; 3-32.

[27] Moon NS, Di Stefano L, Morris EJ, Patel R, White K, Dyson NJ (2008). E2F and p53 induce apoptosis independently during Drosophila development but intersect in the context of DNA damage. PLoS Genet 4(8):e1000153.

[28] Ilhan A, Gurel A, Armutcu F, Kamisli S, Iraz M (2005) Antiepileptogenic and antioxidant effects of Nigella sativa oil against pentylenetetrazol-induced kindling in mice. Neuropharmacology 49: 456-64.

[29] López, M. J. Jordán, and M. J. Pascual-Villalobos, “Toxic compounds in essential oils of coriander, caraway and basil active against stored rice pests," Journal of Stored Products Research, vol. 44, no. 3, pp. 273-278, 2008.

[30] Hayat MA (2009) Method of cancer diagnosis, therapy and prognosis. Springer press vol. 5; 514p.

[31] Kubo, K. I. Fujita, A. Kubo, K. I. Nihei, and T. Ogura, "Antibacterial activity of coriander volatile compounds against Salmonella choleraesuis," Journal of Agricultural and Food Chemistry, vol. 52, no. 11, pp. 3329-3332, 2004

[32] Zafar H, Ali S (2013) Boron inhibits the proliferating cell nuclear antigen index, molybdenum containing proteins and ameliorates oxidative stress in hepatocellular carcinoma. Arch Biochem Biophys 529(2):66-74. 
[33] Jackson PE, Qian GS, Friesen MD, Zhu YR, Lu P, Wang JB, Wu Y, Kensler TW, Vogelstein B, Groopman JD (2001) Specific p53 mutations detected in plasma and tumors of hepatocellular carcinoma patients by electrospray ionization mass spectrometry. Cancer Res ; 61(1):33-5.
[34] Kanter M, Coskun O, Uysal H (2006) The antioxidative and antihistaminic effect of Nigella sativa and its major constituent, thymoquinone on ethanolinduced gastric mucosal damage. Arch Toxicol 80: 217-24. 